\title{
Olhando a cidade: a presença/ausência do Monumento a Olavo Bilac e seus fragmentos
}

\author{
Amanda Batista Bento ${ }^{1}$ \\ DOI 10.20396/eha.vil4.3335
}

Com base no estudo das esculturas "O Escoteiro", "Pátria” e "Via Láctea”, expostas em Memória da Amnésia² como fragmentos de um monumento maior, o Monumento a Olavo Bilac, bem como das outras esculturas que compunham o mesmo monumento e que hoje se encontram em diferentes locais da cidade, buscaremos discorrer sobre as questões envolvidas nos modos de olhar e de perceber a inserção de esculturas no espaço público, considerando os seus significados simbólicos e o seu deslocamento e locomoção pela cidade ${ }^{3}$.

Obra do artista sueco William Zadig, o Monumento a Olavo Bilac [figura 1] foi inaugurado em 1922, no belvedere da Avenida Paulista, e retirado do local em 1936. Esse processo resultou no desmembramento do monumento em oito esculturas singulares, das quais seis estão espalhadas pela cidade e duas encontram-se em depósito4.

De forma a dialogar com o tema do Encontro de História da Arte deste ano, Histórias do Olhar, na presente comunicação, focaremos menos no histórico do monumento ou em sua composição estética, e mais em como ele foi visto e interpretado em seu momento inicial e após sua fragmentação, perpassando pelos modos de olhar a sua presença/ausência na cultura visual de São Paulo, cidade que ecoa sua constante transformação, sobretudo, no caso desse monumento peculiar. ${ }^{5}$

\footnotetext{
1 Graduanda em História da Arte pela Escola de Filosofia, Letras e Ciências Humanas da Universidade Federal de São Paulo (EFLCH/Unifesp). E-mail: amandabbha@gmail.com

2 Exposição organizada por Giselle Beiguelman, aberta ao público entre dezembro de 2015 e abril de 2016, no Arquivo Histórico de São Paulo. Nessa exposição, a artista-pesquisadora explorou as potencialidades de esculturas abandonadas no depósito do Canindé, expondo-as de forma a evidenciar sua invisibilidade e abordando a memória a partir do ponto de vista do esquecimento. Além das esculturas em depósito, a pesquisa de Beiguelman abarcou, também, as obras de arte em logradouros públicos que já foram locomovidas espacialmente pela cidade, trabalho que resultou no mapeamento intitulado Guia dos Monumentos Nômades.

3 Esta comunicação é um recorte da pesquisa de Iniciação Científica intitulada "Valores e significados atribuídos às esculturas em logradouros públicos: o caso do monumento a Olavo Bilac", orientada pela Profa. Dra. Manoela Rossinetti Rufinoni. A pesquisa conta com financiamento da FAPESP, processo de número 2018/22725-0.

4 O nome de seus fragmentos e suas respectivas localizações são: "Pátria" e "Via Láctea": depósito da Secretaria Municipal de Cultura no Canindé; "Busto de Olavo Bilac": Avenida Sargento Mário Kozel Filho, Comando Militar do Sudeste (II Exército), Ibirapuera; "O Caçador de Esmeraldas": E. E. Fernão Dias, Pinheiros; "Pátria e Família": Praça José Moreno, Tatuapé; "Tarde": Parque da Independência, Ipiranga; "Beijo Eterno": Largo São Francisco, centro da cidade; e "O Escoteiro": Parque Ecológico do Tietê.

5 Diversos outros monumentos que se localizam em logradouros públicos da cidade de São Paulo foram realocados. Segundo levantamento feito por Beiguelman (2016), até 2015, registravam-se 63 monumentos que já sofreram processo de realocação pelo menos uma vez. É possível visualizar os deslocamentos dos monumentos na cidade de São Paulo acessando o Guia dos Monumentos Nômades, desenvolvido por Giovanna
} 
Os diversos olhares que se voltaram para o Monumento a Olavo Bilac

Desde sua inauguração o monumento recebeu várias críticas. Existem diversos registros que mencionam o monumento como "feio", a exemplo do Álbum Iconográfico da Avenida Paulista, de Benedito Lima de Toledo, no qual o arquiteto afirma que o monumento "não tinha unidade plástica e, pior que isso, não tinha poesia"'. A matéria de 20/02/1946 d'O Estado de São Paulo, afirma que, ao invés de embelezar, o monumento fazia era "afeiar os logradouros" e que, ao ser retirado de seu local de origem "teve o merecido destino". Já após as matérias de 07/11/1922 e 25/11/1922 ${ }^{8}$ do jornal A Cazeta, que evidenciam críticas ao monumento, em dezembro do mesmo ano, o mesmo jornal publicou o dossiê "Exame res non verba", reunindo críticas feitas por diversas instâncias sociais ao monumento e defendendo sua demolição.

Em sua dissertação acerca do Monumento a Carlos Comes, Fanny Lopes (2012) estabelece paralelos entre o monumento citado e o Monumento a Olavo Bilac, por terem sido inaugurados em um mesmo contexto, de comemoração ao Centenário da Independência, e por terem uma composição espacial muito semelhante. Além dos paralelos, Lopes também apresenta a crítica de Monteiro Lobato ao monumento que, em 1922, se referiu à obra com desprezo, pedindo sua demolição.

A opinião pública já o classificou desde o primeiro dia: monstrengo. Eé, de fato, um perfeito monstrengo, só concebível nas pequenas cidades do interior, onde qualquer "curioso" amassador de barro embasbaca vereadores e guinda-se à cúmplice de Miguel Arcanjo.

(...) Tão flagrante é o desastre que só há um comentário possível: demolição simples. O respeito à memória de Bilac, e o respeito que a cidade deve a si própria, exigem uma coisa só: que aquele bronze volte para o forno. ${ }^{9}$

Em 1936, a pretexto de reforma urbana, ocorreu a retirada do monumento do belvedere da Avenida Paulista, processo que resultou em sua fragmentação e na demolição de sua base arquitetônica. Os fragmentos do monumento foram, então, levados para depósito. A partir daí, cada fragmento ganha uma trajetória particular.

Dos três fragmentos que se encontravam abandonados em depósito a mais de oitenta anos

Casimiro e Mariana Lima, como parte do Projeto Memória da Amnésia, de Giselle Beiguelman. <http://www.desvirtual.com/mda/guia-dosmonumentos-nomades/>, acesso em dez. 2019.

6 TOLEDO, 1987, p. 21

7 Seguindo Heloisa Barbuy (2017) "Com ele [este artigo publicado pelo jornal] o periódico começou uma campanha ferrenha, em um primeiro momento, pela refundição do bloco central [do Monumento a Olavo Bilac], mas que logo passou a pleitear a demolição da obra inteira." (BARBUY, 2017, p. 237)

8 Publicação de um relatório com o histórico da obra e de suas despesas.

9 LOBATO, 1922 apud LOPES, 2012, p. 95 


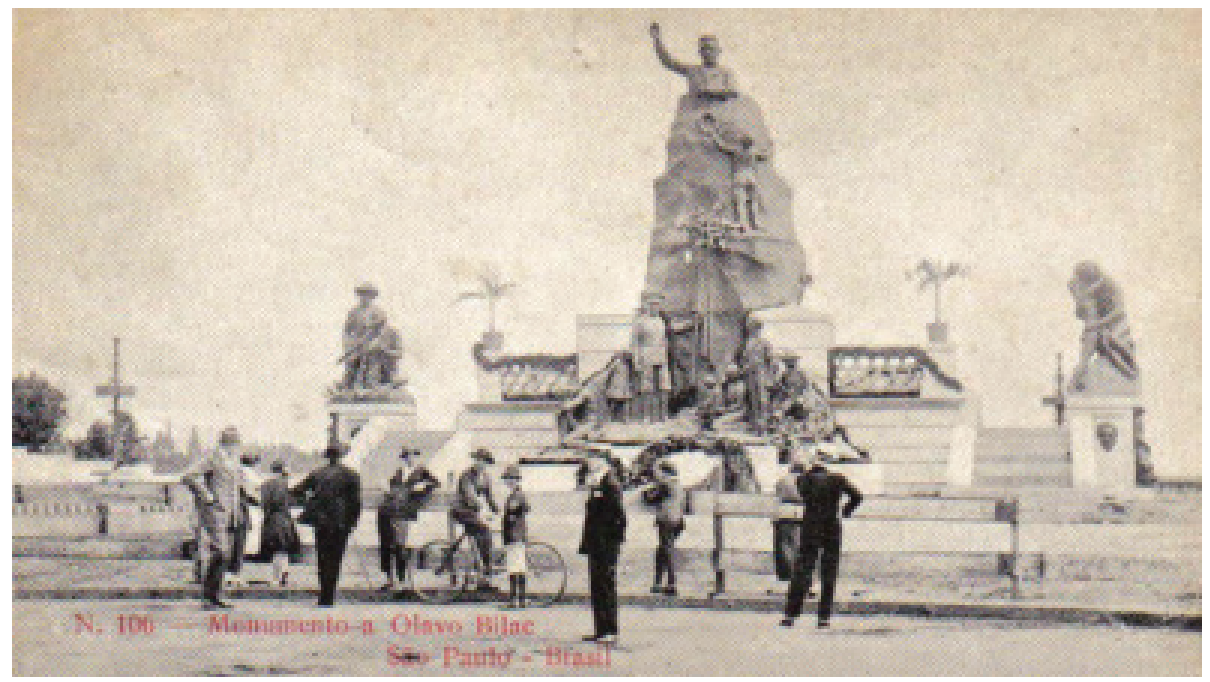

[Figura 1] Postal do Monumento a Olavo Bilac, no belvedere da Avenida Paulista (altura da Rua Minas Cerais), em 1922.

Fonte: TOLEDO, Benedito Lima de. Álbum Iconográfico da Avenida Paulista. São

Paulo: Ex Libris, 1987, p. 25. Crédito da fotografia: João Baptista Monteiro da Silva.

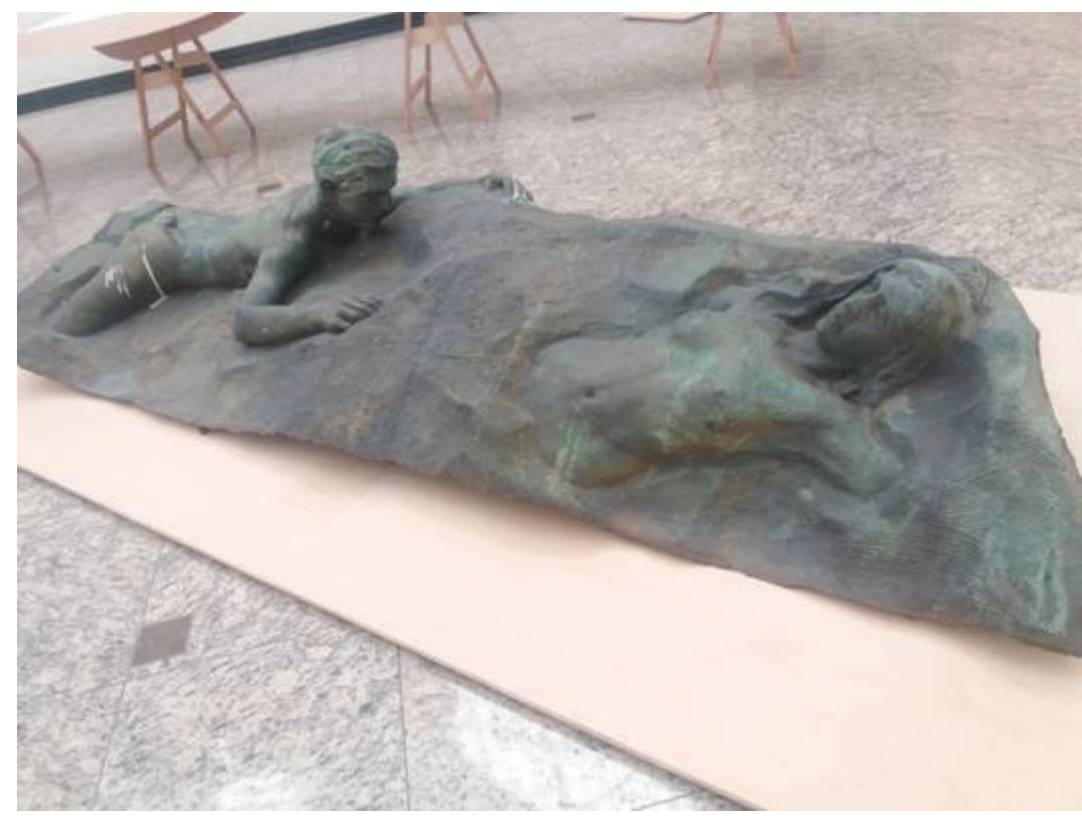

[Figuras 2 e 3] fragmentos "Pátria" e "Via Láctea", respectivamente, na exposição Memória da Amnésia. Fotografia de Alice Américo, 2016.

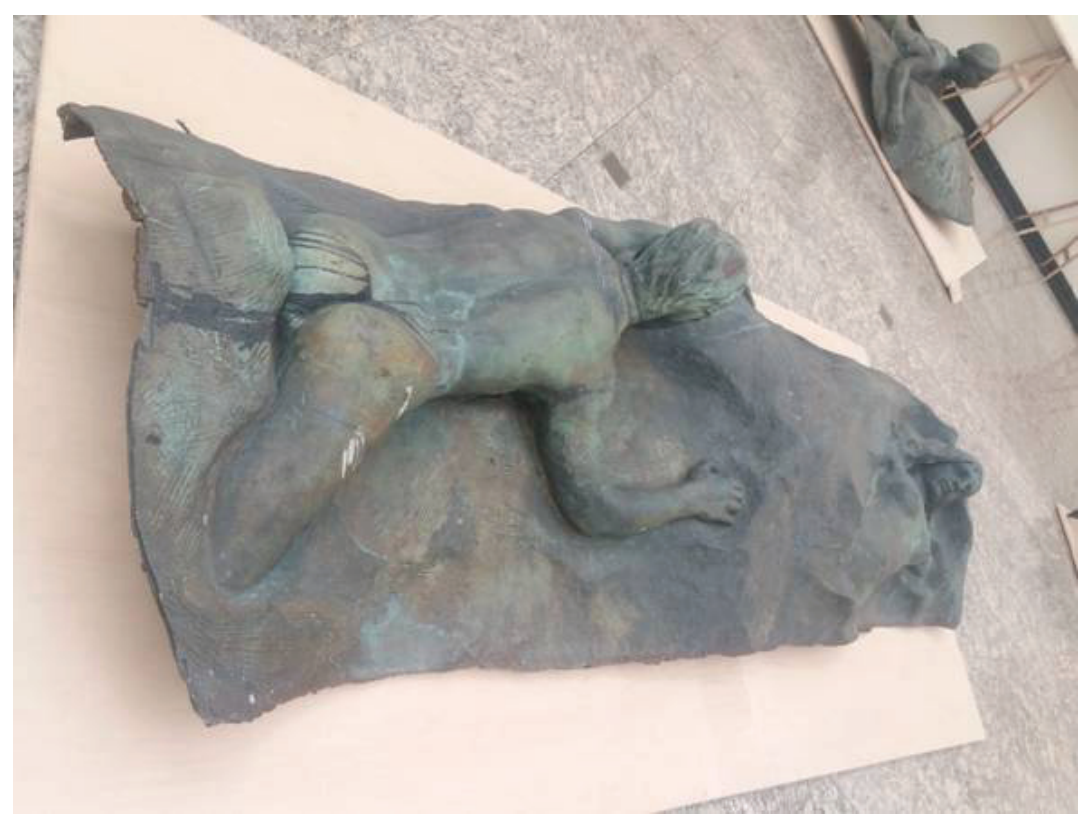


e que compuseram a exposição Memória da Amnésia, em 2015, dois deles continuam em depósito e um retornou para $\operatorname{cidade}^{10}$. A expografia optou por apresentar os monumentos deitados, na horizontal, de forma a inverter a ideia de monumentalidade, intrínseca às obras, mas que já não mais existia pelo seu abandono no depósito"11.

Trata-se de obras de tal forma desenraizadas que, ao longo dos anos, foram se conformando a esses espaços supostamente temporários. Isso faz com que elas tenham suas histórias cada vez mais vinculadas aos territórios provisórios dos depósitos e menos aos seus locais originais. $^{12}$

As figuras 2 e 3 apresentam os fragmentos "Pátria" e "Via Láctea", partes que se localizavam na colina central ao monumento e que agora se encontram desmembrados. "Pátria" se localizava na parte frontal do monumento, e "Via láctea" na parte posterior. Eles se distinguem dos demais fragmentos por possuírem a necessidade estética de integração ao conjunto do monumento, visto que se localizavam na colina e, desmembrados dela, perderam grande parte de sua composição tridimensional. Fragmentos como "Beijo Eterno" (à direita) e "O Caçador de Esmeraldas" (à esquerda), no mesmo no monumento, localizavam-se espacialmente separados de sua parte central, nas laterais da escadaria. Já os fragmentos “Tarde”, "Pátria e família” e "O Escoteiro”, localizados na parte central inferior do monumento, compunham um mesmo bloco e, após sua separação do conjunto escultórico como um todo, também foram fragmentados entre si. Dessa forma, as três esculturas que foram esculpidas grudadas umas nas outras, foram separadas. Por consequência, ao serem fragmentadas, foi preciso preencher com concreto a parte posterior das esculturas ${ }^{13}$, de forma a recuperar sua tridimensionalidade, como podemos observar na figura $4 .{ }^{14}$

É possível levantarmos a hipótese de que a composição tridimensional completa de cada fragmento tenha sido um fato decisivo para o retorno de cada um deles às ruas. Os primeiros fragmentos a saírem do depósito foram justamente os que, mesmo desmembrados do conjunto escultórico, possuem uma tridimensionalidade completa, de forma a serem lidos facilmente mesmo

\footnotetext{
10 A exposição não possuiu um caráter restaurativo ou de realocação das obras na cidade, mas sim de cunho artístico, buscando evidenciar o esquecimento no campo das políticas de memória.

11 Beiguelman (2019) destaca que os depósitos de monumentos são comuns e existem como local transitório para abrigar esculturas quando retiradas da cidade por questões de reforma urbana, mas que preveem que elas retornem ao seu local ao fim da reforma. Na prática, os depósitos da cidade de São Paulo abrigam obras abandonadas, sem previsão de saída. O caso dos fragmentos do Monumento a Olavo Bilac expostos, por exemplo, estavam em depósito a mais de oitenta anos.

12 BEIGUELMAN, 2019, p. 78

13 O monumento de bronze era oco.

14 Até o presente momento da pesquisa não foram encontradas fotografias que elucidem como as partes de trás desses fragmentos eram compostas no projeto original.
} 
separados do conjunto escultórico. Este é o caso de "Beijo eterno" e "O Caçador de Esmeraldas". Já os dois fragmentos que permanecem em depósito até hoje são justamente os que possuem uma maior dependência do conjunto escultórico. Quando fragmentado, em 1936, as partes da "colina" que apresentavam figuras "saindo" dela, foram conservadas, mas o restante da colina foi descartado. De qualquer forma, mesmo se toda a colina tivesse sido conservada e ela fosse reintegrada de forma separada dos demais fragmentos, esta teria uma composição inusitada e de difícil leitura e compreensão, a não ser que fosse reintegrada com o busto em seu topo. Mas essas são apenas suposições, visto que apenas parte da colina foi conservada. Por fim, fica difícil imaginar como seria a reinserção dos fragmentos "Pátria" e "Via Láctea" na paisagem urbana, mas somente o tempo responderá se eles permanecerão abandonados em depósito ou se será encontrada alguma solução que possibilite seu retorno aos logradouros públicos. Por enquanto, a imagem desses fragmentos na cidade é possível apenas em nossa imaginação.

O fragmento "O Escoteiro", que compôs a exposição Memórias da Amnésia, foi restaurado em 2018 e em 2019 retornou para o espaço público, localizando-se hoje no Centro Esportivo do Tietê. A saída desse fragmento do depósito e sua nova alocação ocorreram recentemente, ao longo da presente pesquisa, portanto, ainda não foi possível estudar detidamente a forma e os impactos de sua reinserção na cidade.

O busto de Olavo Bilac localizava-se no topo da colina, de forma a destacar a personalidade homenageada no monumento. Hoje, este fragmento encontra-se em cima de um pedestal e atrás das grades que cercam o Comando Militar do Sudeste (II Exército), na Avenida Sargento Mário Kozel Filho, Ibirapuera [figura 5]. É incomparável a imponência que o busto possuía no monumento e a forma como se encontra hoje. Apesar de ser o fragmento mais bem conservado e estar acomodado em um pedestal, este não transpassa a monumentalidade que o busto teve em seu primeiro momento. Hoje, quando visualizado, nem se imagina que o busto fora retirado de um conjunto escultórico monumental, já que a obra possui certa independência quando exposta isoladamente.

Já o fragmento "Tarde" encontra-se desde 1988 no Parque da Independência. Apesar da monumentalidade que o local exala, a pequena escultura está camuflada na imponência do cenário, localizando-se numa das escadarias laterais do jardim do Museu do Ipiranga [figura 6]. Ao voltar o olhar para o fragmento, naturalmente vem à memória outra escultura, a obra "O Pensador" de Auguste Rodin, pois ambas as esculturas possuem uma composição semelhante. Entretanto, a obra de Zadig faz alusão a um livro de Bilac, publicado postumamente, homônimo à escultura.

Homônimo a um poema de Bilac que referencia Fernão Dias, o fragmento "O Caçador de Es- 
[Figura 4]

vista lateral do fragmento "Pátria e Família", evidenciando a base e o preenchimento da escultura com concreto, de forma a recompô-la como uma unidade. Fotografia da autora, 2019.

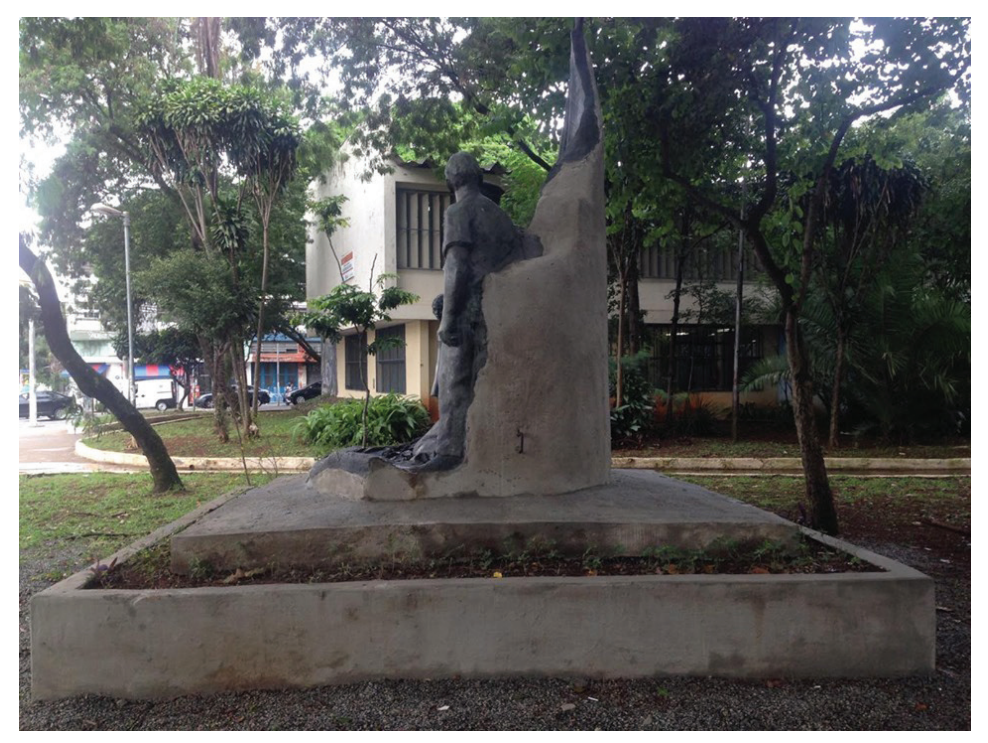

[Figura 5]

Busto de Olavo Bilac, localizado dentro do Comando Militar do Sudeste (II Exército), no lbirapuera.

Fotografia da autora, 2019.

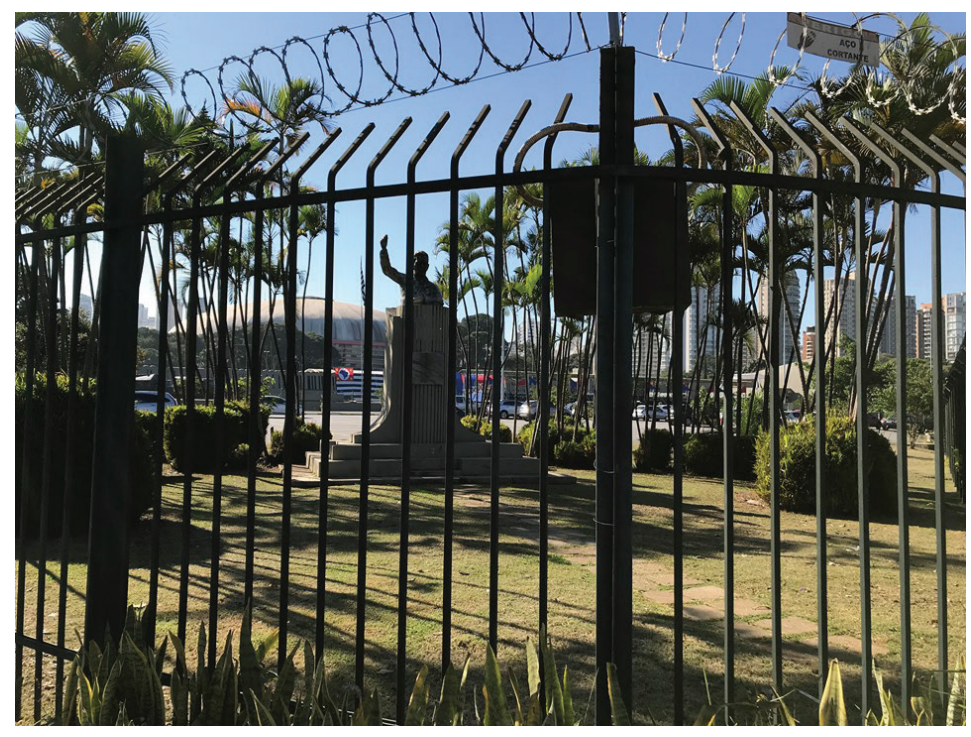

[Figura 6]

Escultura "Tarde", localizada no

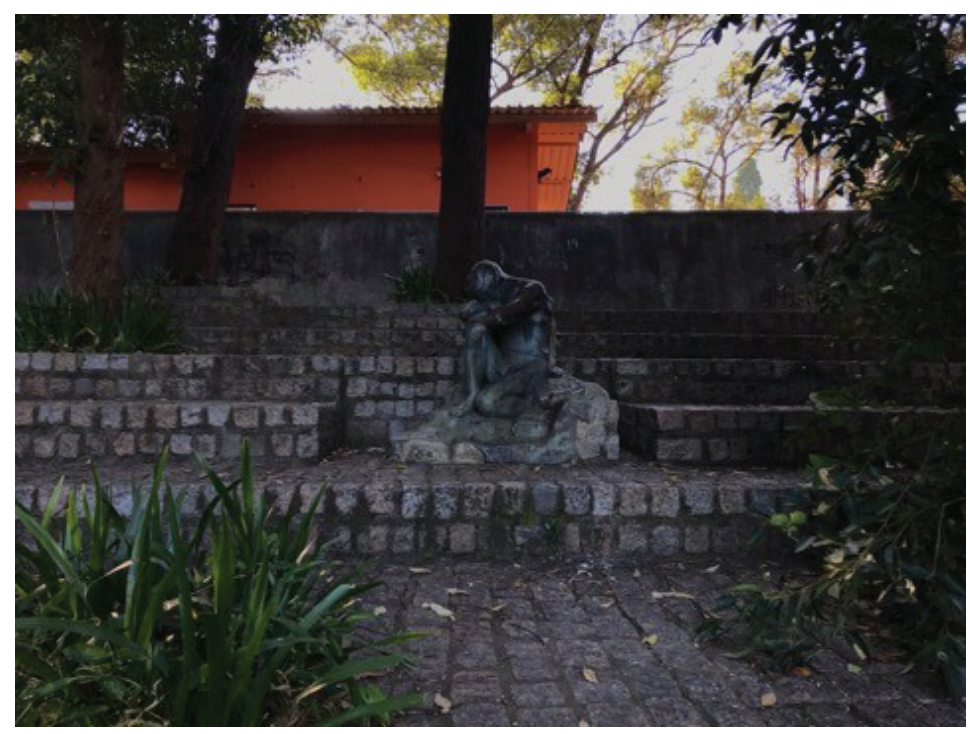

Fotografia da autora, 2019. 


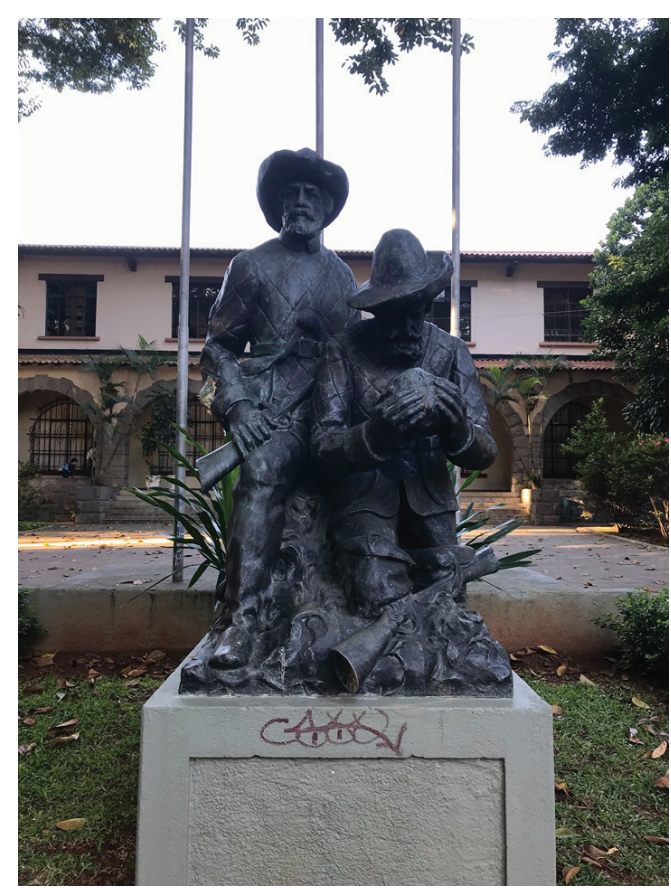

[Figura 7] escultura "O Caçador de Esmeraldas", localizada na Escola Estadual Fernão Dias.

Fotografia da autora, 2019.
[Figura 9]

escultura "Pátria e Família", localizada na praça José Moreno. Fotografia da autora, 2019

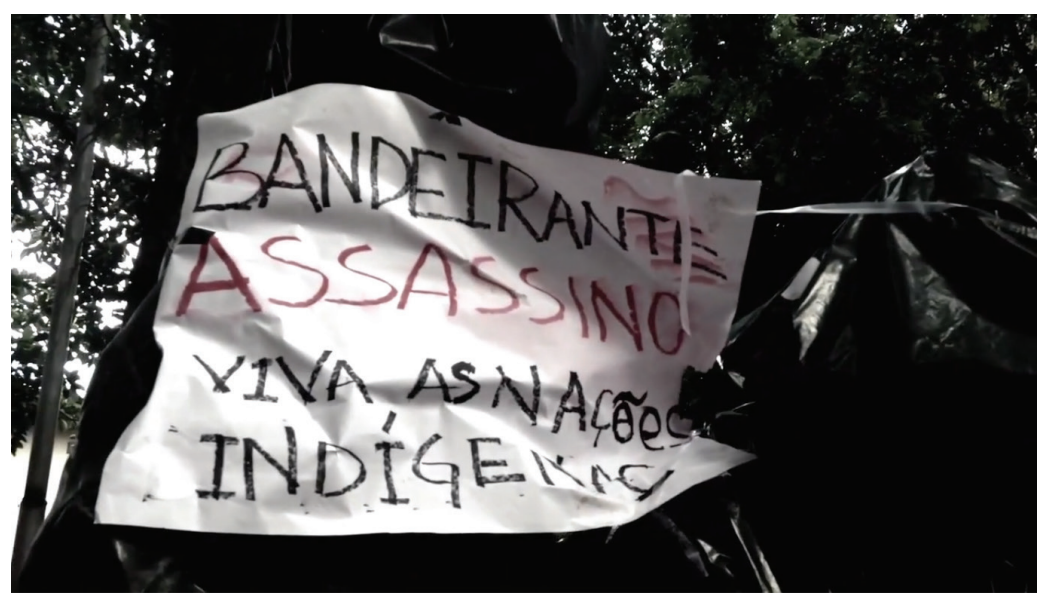

[Figura 8] Intervenção sobre o fragmento "O Caçador de Esmeraldas", na Escola Estadual Fernão Dias.

Frame do vídeo Memória da Amnésia, elaborado como documentação da exposição Memória da Amnésia. Direção e imagem por Cleisson Vidal, projeto de Giselle Beiguelman. O vídeo está disponível em: <https://vimeo.com/161144900>, acesso em dez. 2019.
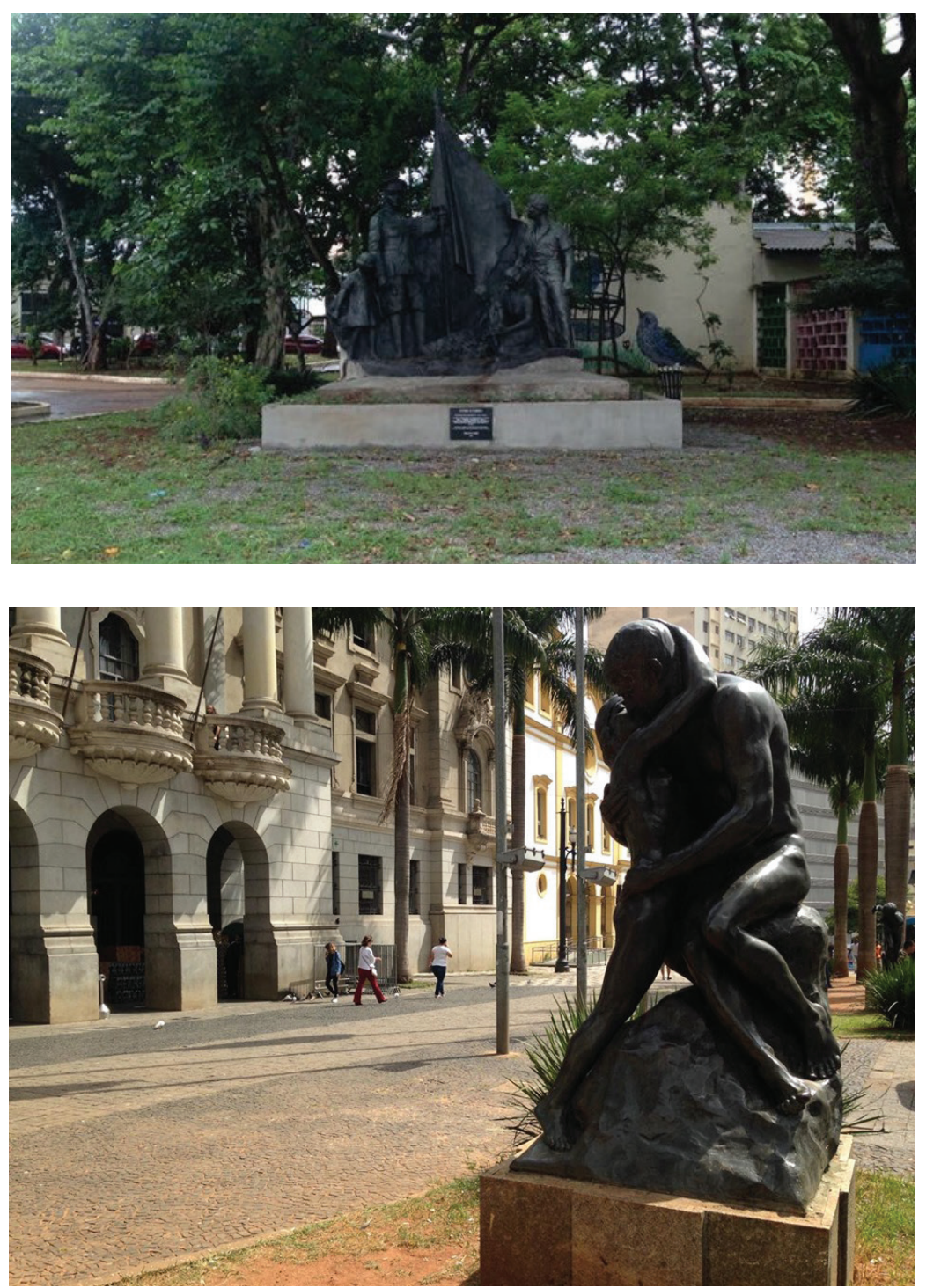

Fotografia da autora, 2019. 
meraldas" [figura 7] se encontra hoje na Escola Estadual Fernão Dias, em Pinheiros. A escultura retrata a figura de dois bandeirantes, exaltando o bandeirantismo. ${ }^{15}$ As obras de arte que representam bandeirantes, situadas em logradouros públicos, têm sofrido constantes intervenções críticas por parte de determinados grupos sociais, como é o caso do Monumento às Bandeiras e da Estátua de Borba Gato, de forma a problematizar a narrativa histórica que privilegiava a figura do bandeirante como um personagem heroico, contexto em que a presença dessas obras no espaço urbano tem sido revista e reinventada. Nesse contexto, a escultura de Zadig não ficou de fora, como podemos observar na figura 8. Trata-se do registro de uma intervenção em que foram colocados sacos de lixo sobre a cabeça dos personagens, além de um cartaz escrito "Bandeirante Assassino. Viva as nações indígenas". A partir desse exemplo, evidenciamos que, ao mudar de época/contexto, as obras e os personagens representados são olhados e interpretados de formas diferentes.

O fragmento "Pátria e Família" [figuras 4 e 9] localiza-se hoje na Praça José Moreno, Tatuapé. Entretanto, este não foi o primeiro destino da escultura após sair de depósito. Em 1987 a escultura foi instalada na Avenida Salim Farah Maluf, no cruzamento com a Avenida Celso Garcia. Apesar de, até o presente momento da pesquisa, não termos encontrado registros fotográficos da escultura no cruzamento destas duas grandes avenidas, precisamos recorrer a nossa imaginação para tentar visualizar a dificuldade de fruição de uma obra que se localiza no interior de uma movimentação intensa e caótica. A obra foi retirada do local por motivos de reforma urbana. Hoje, ela se encontra em uma praça, local que possibilita um maior contato com a obra.

É importante refletirmos não somente sobre como as obras eram visualizadas quando integradas ao conjunto escultórico em oposição a como elas são visualizadas de forma fragmentada, mas também sobre como cada fragmento foi visto por cada local pelo qual passou. O fragmento "Beijo Eterno", hoje localizado no Largo São Francisco, é uma das esculturas que mais vagou pela cidade. Em 1956, a escultura saiu do depósito para ser reimplantada no Largo do Cambuci, entretanto, o olhar da sociedade moralista da época achou a escultura obscena por representar uma índia e um europeu, ambos nus se beijando. Após estas reclamações, a escultura retornou para depósito, de onde foi novamente retirada dez anos após esse caso, desta vez com destino ao túnel da Avenida Nove de Julho. Após sofrer novos julgamentos morais, "os estudantes de Direito da USP [Universidade de São Paulo] transportaram aquele monumento da Av. 9 de Julho para o 'território livre',

15 O bandeirante foi constantemente retratado como herói em um contexto de construção da identidade nacional, no I Centenário da Independência. As obras criados neste contexto ilustravam sentimentos eminentemente nacionais. No Monumento a Olavo Bilac, esses sentimentos se fazem presentes através da figura do bandeirante, do indígena e do europeu. 
conta a matéria do jornal O Estado de S. Paulo de 19/10/1966, expondo o feito ocorrido no dia anterior à publicação. Os estudantes ${ }^{16}$ consideravam o Largo como um "território livre" onde a escultura não sofreria mais os julgamentos da sociedade moralista. Ali, a escultura estaria protegida, e é onde ela se encontra desde então. Com este caso, podemos observar que a escultura foi lida de forma diferente ao mudar de território, em um mesmo período histórico.

\section{Considerações Finais}

A partir do exposto e da reflexão sobre como se olhava para o Monumento a Olavo Bilac em seu projeto original e como seus fragmentos são vistos hoje, perpassando pelas formas como uma mesma escultura é olhada de maneiras diferente ao mudar de ambiente ou época/contexto, intentamos refletir sobre como se dá o olhar para uma cidade em constante transformação. O monumento aqui abordado é um ótimo exemplo para trazer à tona tais reflexões, por envolver diversas questões, desde o descaso com o patrimônio histórico e as circunstâncias envolvidas em sua retirada do local de origem, até os desdobramentos relacionados aos diferentes destinos conferidos a cada fragmento: do abandono em depósito à reinserção na cidade. Essas questões dizem respeito não apenas à forma como o monumento e seus posteriores fragmentos se inserem no contexto urbano, mas também aos modos de olhá-los e de interpretá-los ao longo do tempo, em cada nova situação urbana.

\footnotetext{
16 O grupo de estudantes que fez a locomoção da escultura para o Largo é identificado no jornal Diário Popular, de 16/10/1996, como "Grupo II, também conhecidos como Canalhas, ligado ao Centro Acadêmico 11 de Agosto". O Centro Acadêmico e os estudantes da Faculdade de Direito do Largo São Francisco possuem uma relação direta com o monumento, pois foi o centro acadêmico da faculdade que encomendou o monumento e que angariou os fundos que financiaram sua ereção.
} 


\section{Referências bibliográficas}

A Gazeta, São Paulo, 25 nov. 1922.

Abantesmas da cidade. O Estado de São Paulo, São Paulo, 20 fev. 1946.

BARBUY, Heloisa. Grupo escultórico Beijo Eterno. In As Esculturas da Faculdade de Direito. Cotia, SP: Ateliê Editorial; São Paulo: Faculdade de Direito da Universidade de São Paulo, p. 226-243, 2017.

BEICUELMAN, Giselle. Memória da Amnésia. Da cidade interativa às memórias corrompidas: arte, design e patrimônio histórico na cultura urbana contemporânea. São Paulo: Tese apresentada à Faculdade de Arquitetura e Urbanismo da Universidade de São Paulo para obtenção do título de Livre-Docente junto ao Depto. de História da Arquitetura e Estética do Projeto, p. 221-243, 2016.

Memória da Amnésia. In Memória da amnésia: Políticas do esquecimento. São Paulo: Edições Sesc São Paulo, p. 76-137, 2019.

Diário Popular, São Paulo, 16 out. 1996.

LOPES, Fanny Tamisa. O Monumento a Olavo Bilac de William Zadig. In Cenografia e paisagem urbana: um estudo de caso na cidade de São Paulo. Dissertação apresentada à Universidade Estadual de Campinas, p. 93-99, 2012.

Não é um Monumento a Olavo Bilac; É um atentado à Memória do Insigne Patriota. A Gazeta, São Paulo, 07 nov. 1922. TOLEDO, Benedito Lima de. Álbum Iconográfico da Avenida Paulista. São Paulo: Ex Libris, 1987.

VIMEO. Documentação da exposição Memória da Amnésia por Cleisson Vidal. Disponível em: <https://vimeo. com/161144900>, acesso em dez. 2019.

XI de Agosto quer a estátua. O Estado de São Paulo, São Paulo, 19 out. 1966. 